\title{
Qualitative Study of Factors Affecting Patient, Caregiver and Physician Preferences for Treatment of Myeloma and Indolent Lymphoma
}

This article was published in the following Dove Press journal: Patient Preference and Adherence

\author{
Wei-Ying Jen (D) \\ Joanne Yoong ${ }^{2}$ \\ Xin Liu (D) \\ Melinda Si Yun Tan ${ }^{3}$ \\ Wee Joo Chng' \\ Yen-Lin Chee' \\ 'Department of Haematology-Oncology, \\ National University Cancer Institute, \\ Singapore; ${ }^{2}$ Centre for Health Services \\ and Policy Research, Saw Swee Hock \\ School of Public Health, National \\ University of Singapore, Singapore; \\ ${ }^{3}$ Department of Haematology, Singapore \\ General Hospital, Singapore
}

Introduction: The number of treatment options for myeloma and indolent lymphoma are expanding at an exponential rate, with few direct head-to-head comparisons on which to base efficacy measures. We sought to understand how patients, their caregivers and physicians weigh treatment characteristics in order to come to a decision on which treatment option to pursue.

Methods: Patients, their caregivers and physicians were recruited and interviewed until data saturation was reached. A qualitative, thematic analysis was done to identify themes important to each stakeholder.

Results: We found that, while all three groups valued efficacy the most, the consideration of other secondary characteristics of the treatment, such as cost, toxicity and logistical issues all differed subtly between the different groups. Patients valued minimising cost and toxicity, even at small trade-offs in efficacy. Caregivers and physicians valued efficacy foremost.

Conclusion: Acknowledging and managing these differences is paramount because they influence shared decision-making and may affect patient outcomes in the short term, as well as their more general well-being in the long term.

Keywords: patient preferences, treatment options, myeloma, lymphoma

\section{Introduction}

Myeloma and indolent lymphoma are common haematological malignancies which are increasing in incidence and prevalence. The age-standardised rate from 2008 to 2012 in Singapore was 13.4 per 100,000 per year; lymphoid neoplasms are now the fifth most common cancer amongst males in Singapore. ${ }^{1}$ Treatment advances are transforming these conditions into chronic diseases, with a resultant increase in disease burden. This is projected to increase exponentially as the population ages and disease survival increases. $^{2,3}$

Advances in medical science have led to the development of multiple classes of agents for the treatment of myeloma and indolent lymphoma, each with their own distinct mechanisms of action, toxicity profile, route of administration, treatment schedule and cost. ${ }^{4,5}$ Most myeloma treatment regimens are triplet-based or quadruplet-based regimens comprising a proteasome inhibitor, an immunomodulatory agent, a steroid or a monoclonal antibody. ${ }^{6,7}$ For the indolent lymphomas, treatment options range from conventional chemotherapy to monoclonal antibodies and, more recently, targeted therapies. ${ }^{8,9}$ Unfortunately, there is a dearth of high-quality evidence directly comparing available treatment options, leaving comparative data scarce. ${ }^{10}$ Treatment choice is hence often made by stakeholders (physicians, patients
Correspondence: Wei-Ying Jen Department of Haematology-Oncology, National University Cancer Institute, I Kent Ridge Road, NUHS Tower Block Level 7, I 19228, Singapore

Tel +6567725286

Fax +6567722998

Email wei_ying_jen@nuhs.edu.sg 
and their caregivers) based on variable clinical and nonclinical factors, depending on their perspectives, priorities and degrees of participation in the decision-making process.

Few studies have examined how these stakeholders assess treatment options, and how differences in individual priorities may affect treatment choices, particularly for novel agents. With the advent of shared decision-making and changing laws on counselling and patient consent, ${ }^{11}$ physician cognizance of patient preferences is paramount to ensuring they are provided with all pertinent information. In this study, we aim to examine the factors which decision-makers feel are important in selecting a treatment regimen.

\section{Methods}

This study was a qualitative interview study. This allowed the researchers to identify factors considered important by patients, caregivers and physicians in selecting a treatment regimen and formed the basis of a discrete choice experiment which is now in progress.

\section{Participants}

The recruitment period ran from 1 July 2018 to 31 December 2018. Consecutive patients were recruited by their treating physicians from the inpatient Haematology service as well as disease-specific lymphoma and myeloma clinics. These clinics are run at least twice weekly and see patients across the disease spectrum - newly-diagnosed, on active treatment, relapsed and in remission. The only exclusion criteria were patients who were unable to communicate or who were seriously ill (in high-dependency and intensive care units). Patients were asked to nominate one caregiver, who was recruited to give the caregiver's perspective. In order to capture the physician's perspective, we interviewed six physicians who sub-specialise in either lymphoma or myeloma treatment. Physicians were recruited from the two tertiary Haematology centres in Singapore - the National University Cancer Institute (NCIS) at the National University Hospital (NUH) and the Singapore General Hospital (SGH).

All participants gave written informed consent; the study was approved by our institutional ethics review board (National Healthcare Group Domain Specific Review Board 2018/00118), and was conducted in accordance with the Declaration of Helsinki.

\section{Sample Size}

The sample size for qualitative studies is guided by the point at which the number at which data saturation is reached. ${ }^{12}$
We defined data saturation in this study as the point at which interview themes began to repeat themselves. A total of 12 patients, 12 caregivers and 6 physicians were interviewed. For the patients, a mix of fully paying (private) and government-subsidized patients, and patients who had relapsed, were in remission or newly-diagnosed were recruited. This was to ensure that the study included patients and caregivers from varying backgrounds, and with a range of treatment exposures and experiences.

\section{Interviews}

Patients and their nominated caregiver (usually a firstdegree family member - either spouse or children) were interviewed separately. All interviews were recorded. No participants declined to be recorded. Interviews were conducted by trained research assistants in a private room in English or Mandarin. Physicians who consented to take part in the study were interviewed separately.

Interviews were semi-structured, using an openended questioning and facilitated by a topic guide (Appendix 1). They were conducted by trained qualitative researchers led by a post-doctoral qualitative researcher (Acknowledgements). Researchers were independent of the treating team to reduce bias and to encourage openness. Each interview lasted 60 mins. Field notes were collected during the interview and used in the thematic analysis. Participants were encouraged to recall their experiences of their diagnosis and the initial discussions surrounding treatment. They were asked about their concerns and expectations, and whether there had been any changes in these over the course of their treatment.

Interviews were transcribed verbatim; interviews that were conducted into Mandarin were first translated into English by an experienced translator.

\section{Analysis}

A thematic analysis was performed. ${ }^{13,14}$ All analyses followed the same process for each of the three participant groups (physicians, patients, caregivers). Three team members independently coded two interviews through inductive reasoning. Discussions about the coding followed, and an agreement on an initial codebook was reached. Following the development of the initial codebook, the remaining transcripts for the participant group were coded. Further discussion between the team members took place to clarify and refine the codes. For purposes of reliability, a selection of the interviews was independently coded to verify the codes. 
Once all the interviews in each participant group were coded, the codebook was discussed, refined and a final the final thematic structure for each group was agreed upon.

NVivo 12 (QSR International, Australia) was used to organise and manage all qualitative analysis.

\section{Results}

Results are reported in accordance with published consolidated criteria. ${ }^{15}$

\section{Baseline Characteristics}

Twelve patients, 12 caregivers and 6 physicians were interviewed. There were nine male patients and three female patients. Of the caregivers, five were male and seven were female. There were four male and two female physicians. The baseline characteristics of the patients are shown in Table 1.

\section{Patients}

Key themes are shown in Table 2 .

Cost was a major issue, with patients often wanting to reserve savings for loved ones rather than deplete them on expensive therapies. This led to potentially less-efficacious choices - "the cheapest available option was chemo, which was the toughest because it has the most side effects"- such as selection of options purely based on available subsidies, or declining treatment altogether, due to financial constraints "If I have to go, I rather go now than cause a strain, financial for my family and then go".

Patients also frequently reported a desire to maximise quality-of-life, with some patients citing adverse side effects as an offsetting consideration as well. However, concerns related to largely individual clinical outcomes were weighed against broader concerns related to minimising the burden to caregivers. Most patients still felt that physician recommendation was a very important factor in choosing a treatment plan - "I have full faith in the doctors". Although some patients cited efficacy as being important, it was brought up relatively infrequently.

\section{Caregivers}

Key themes are shown in Table 3.

Caregivers' concerns tended to focus on the logistical issues related to obtaining treatment, such as access on weekends, streamlining processes, etc. Waiting times and lack of availability of services on weekends were cited as a barrier to acting as caregivers, as many caregivers had to tap into their annual leave allowances to accompany patients to the hospital. Some even exhausted their leave allowances, resulting in them having to take "no pay leave" to accompany patients. Long waiting times also impacted on the amount of time they were able to take away from a regular working day, which added to frustration. As such, they generally preferred loved ones to be at home but believed that practically, hospital was an easier place for treatment because of availability of skilled care (nursing, food requirements, etc.) and the perception of better sterility.

Caregivers were active participants in the decisionmaking process. In some cases, they were the primary communicator with the treatment team or helped to facilitate the care plan discussion between the physicians and the patient. Caregivers were divided between those who respected the patient's autonomy above all else, supporting decisions made primarily by the patient, and those who tried to protect their loved ones from a "tsunami" of information. Some were concerned about their loved one's ability to cope with difficult news - "people don't die because of cancer; they die because of depression. If you are positive, your body will help you heal". Information caregivers cited as withheld from physicians included financial constraints. The priority of caregivers was for physicians to recommend the most efficacious treatment, without worrying about financial constraints. Some

Table I Baseline Characteristics

\begin{tabular}{|c|c|c|c|c|c|c|c|c|c|c|}
\hline \multirow[t]{2}{*}{ Participants } & \multirow[t]{2}{*}{ Interviews } & \multicolumn{2}{|l|}{ Hospital } & \multicolumn{2}{|c|}{ Gender } & \multicolumn{2}{|l|}{ Diagnosis } & \multicolumn{2}{|c|}{ Treatment } & \multirow[t]{2}{*}{ Matched Pairs } \\
\hline & & NUH & SGH & Male & Female & Myeloma & Lymphoma & Ist line & $>1$ & \\
\hline Patients & 12 & 10 & 2 & 9 & 3 & 8 & 4 & 7 & 5 & 4 \\
\hline Caregivers & 12 & $10(+1)^{*}$ & 2 & 5 & $7(+1)^{*}$ & $7(+1)^{\wedge}$ & 4 & $6(+1)^{\wedge}$ & 5 & \\
\hline Physicians & 6 & 4 & 2 & 4 & 2 & & & & & \\
\hline Total & 30 & $24(+1)^{*}$ & 6 & 18 & $12(+1)$ & & & & & \\
\hline
\end{tabular}

Notes: *A paired interview was conducted with two caregivers of the same patient. Although there were two caregivers as participants, they are counted as one because they both care for one unique patient. 'Two interviews were conducted with different caregivers of the same patient. They are counted as one because they both care for one unique patient. 
Table 2 Select Quotes from Patients

\begin{tabular}{|c|c|c|}
\hline Theme & Patient & Quote \\
\hline Efficacy & 6 & $\begin{array}{l}\text { "What you have to tolerate is only temporary. If they tell me this thing can cure me } 100 \% \text {, I would probably still } \\
\text { go for it" }\end{array}$ \\
\hline Cost & I & "Clinical trial doesn't cost ... maybe I will go for that" \\
\hline Cost & 2 & $\begin{array}{l}\text { "Because at the initial stages I, had medical insurance ... and I didn't renew it. It lapsed ... So when these three } \\
\text { options were given to me, the cheapest option available was chemo, which is which is the toughest option } \\
\text { because it has the most side effects. Very terrible." }\end{array}$ \\
\hline Cost & 3 & $\begin{array}{l}\text { "Alright, if I prolong my life for } 5 \text { years, say max tops } 5 \text { years, what am I going to do in } 5 \text { years? I rather save I00k } \\
\text { for my kids who can use it for their studies. So another } 5 \text { more years, I only think I'll watch one more world cup, } \\
\text { that's all. [laughs]" }\end{array}$ \\
\hline Cost & 9 & "If I have to go, I rather go now than cause a strain, financial for my family and then go" \\
\hline $\begin{array}{l}\text { Least burden to } \\
\text { loved one }\end{array}$ & 12 & $\begin{array}{l}\text { "And then uh, especially show that the- you mustn't- in order not for them to worry-you- you must really look } \\
\text { okay-you know?" }\end{array}$ \\
\hline Side effects & 2 & $\begin{array}{l}\text { "I don't think I can cope with another round of chemo because this chemo, I fainted and collapsed. Blood count } \\
\text { dropped and had an infection, my blood pressure dropped, and I had to go to ICU. So I told the doctor, never } \\
\text { mind, I don't think I can go through it." }\end{array}$ \\
\hline $\begin{array}{l}\text { Doctor } \\
\text { recommendation }\end{array}$ & I, 2 & "I have full faith in the doctors." \\
\hline $\begin{array}{l}\text { Doctor } \\
\text { recommendation }\end{array}$ & 12 & $\begin{array}{l}\text { "I strictly follow [name of current hospital] doctor. [Name of current hospital] doctor advise, what is the } \\
\text { planning, I just follow strictly. I didn't go anywhere else to check." }\end{array}$ \\
\hline $\begin{array}{l}\text { Conflict between } \\
\text { caregiver }\end{array}$ & 4 & $\begin{array}{l}\text { "Though my wife and kids will say, no, no you use the money. I don't think so. As I said, adding another 4-5 years } \\
\text { to my life, I don't think there's something great I can do." }\end{array}$ \\
\hline Where treatment is & I & "To me, I would go whatever the treatment requires me to go - not a problem." \\
\hline
\end{tabular}

caregivers reported depleting their savings in order to pursue treatment. This concern was also often not discussed with the patient, as some caregivers feared that the patient would stop treatment if they knew what the treatment cost.

\section{Physicians}

Key themes are shown in Table 4.

Where cost was not an issue (e.g. due to insurance coverage), physicians generally prioritised efficacy and recommendations from international guidelines in selecting treatment regimens. This was followed by tolerability, based on each individual patient's co-morbid conditions and individual characteristics. However, the number of patients for whom cost is not an issue is low; many physicians hence felt constrained by cost, and they felt this was not equitable as patients would have to be offered treatments which were perceived to be less efficacious due to financial constraints - "we are trying to figure out where you can get the money to treat them and whether you can treat them or not".
Physicians also reported being cognizant of differences between caregiver-patient priorities, which they felt sometimes hindered the decision-making process, but found such differences difficult to manage due to the need to maintain the physician-caregiver or patient-caregiver relationship - "sometimes views conflict and my worry is sometimes I don't actually know what the patients want, because they are deferring to their caregivers". In a number of instances, a patient would express certain preferences with a physician, but a different one when a consultation involving all three parties was carried out.

\section{Discussion}

This study describes how patients, their caregivers and treating physicians feel about various treatment characteristics and the interplay between those stakeholders. The results must be interpreted in the context of a healthcare financing system that revolves around means-tested, subsidized care with a mandatory co-payment element. Common major variables include efficacy and cost, while 
Table 3 Select Quotes from Caregivers

\begin{tabular}{|c|c|c|}
\hline Theme & Caregiver & Quote \\
\hline Cost & I & "I mean for the financial parts it's more about how she feels. I spent all my savings on the first treatment" \\
\hline Cost & 11 & $\begin{array}{l}\text { "I apply for no pay leave and come late ... Then I quit my job [laughs]. Then it becomes a concern you } \\
\text { know ... more for the money part." }\end{array}$ \\
\hline Cost & 10 & "I feel significantly burdened by the cost because the cost is significant. It is not something that is minor." \\
\hline Side-effects & 4 & $\begin{array}{l}\text { "She couldn't even smell people cooking ... In a way, it's spoiling her chance of recovery, it really takes away } \\
\text { the quality-of-life from the patient. Technically it worsens the situation." }\end{array}$ \\
\hline Patient autonomy & 9 & $\begin{array}{l}\text { "It really depends on the situation of what the patient wants, and if the patient wants a different kind of } \\
\text { outcome or different design of the treatment, then we are more than happy to discuss with the doctors." }\end{array}$ \\
\hline $\begin{array}{l}\text { Withholding from } \\
\text { patient }\end{array}$ & 2 & $\begin{array}{l}\text { "For example, my biggest concern I don't tell him, (...) Yes. That was, that could be a problem in the long } \\
\text { run." }\end{array}$ \\
\hline $\begin{array}{l}\text { Withholding from } \\
\text { patient }\end{array}$ & 10 & $\begin{array}{l}\text { "My frustration is that she may not make the same rational decisions that we would make when given the } \\
\text { same choices." }\end{array}$ \\
\hline $\begin{array}{l}\text { Withholding from } \\
\text { physician }\end{array}$ & 6 & $\begin{array}{l}\text { "We don't discuss financial stuff with the doctor, but yeah we just trust that the doctors will do their job. We } \\
\text { believe they will do their job and give her the best treatment possible." }\end{array}$ \\
\hline $\begin{array}{l}\text { Doctor } \\
\text { recommendation }\end{array}$ & 11 & $\begin{array}{l}\text { "Definitely you know for us the doctor communicates with us very well. When the doctor said, you are } \\
\text { performing well, she is happy. But if I say: 'you're recovering well', I'm not the doctor, she won't trust me. } \\
\text { 'I don't believe you. You are not the doctor." }\end{array}$ \\
\hline Where treatment is & 4 & $\begin{array}{l}\text { "... home environment where he might be still free to roam around in the house, it's a big concern for us } \\
\text { because if we pick the home-based, my mum will be like, to what extent of cleanliness are we talking about for } \\
\text { cleanliness." }\end{array}$ \\
\hline
\end{tabular}

Table 4 Select Quotes from Physicians

\begin{tabular}{|l|l|l|}
\hline Theme & Physician & Quote \\
\hline Cost & 5 & $\begin{array}{l}\text { "We are trying to figure out where you can get the money to treat them and whether you can treat them or not. } \\
\text { That's very unfair, to base decisions on financial reasons." }\end{array}$ \\
\hline Cost & 4 & $\begin{array}{l}\text { "And quite often if it's cost, they they'll tell me the cost is it. I say okay see if there are ways and means to get around } \\
\text { it, let's just discuss with the social worker. Let's see what funding they can provide, what support we can harness for } \\
\text { you." }\end{array}$ \\
\hline $\begin{array}{l}\text { Need to } \\
\text { treat }\end{array}$ & 2 & $\begin{array}{l}\text { "Usually if they do not want treatment I can always say, "Let's start one with a little bit only, you don't want then we } \\
\text { stop." }\end{array}$ \\
\hline $\begin{array}{l}\text { Patient } \\
\text { factors }\end{array}$ & 3 & $\begin{array}{l}\text { "We keep it patient-centric, for example, some patient might have something more about their disease uh or, or } \\
\text { a non-disease-related factor, for example patient with heart problems or patient with liver problems, when they } \\
\text { come in we say, this is what we use normally but unfortunately given your disease, this I think is going to be a bit } \\
\text { tricky so I would suggest this." }\end{array}$ \\
\hline $\begin{array}{l}\text { Patient } \\
\text { autonomy }\end{array}$ & 5 & $\begin{array}{l}\text { "Sometimes views conflict and my worry is sometimes I don't actually know what the patients want, because they are } \\
\text { deferring to their caregivers" }\end{array}$ \\
\hline $\begin{array}{l}\text { Patient } \\
\text { autonomy }\end{array}$ & 2 & $\begin{array}{l}\text { "There's a cultural difference in how patients and carers make decisions about the treatment and I don't think in our } \\
\text { society we are capturing that at the moment and we are allowing enough information in the correct way to go out to } \\
\text { the patients so that they can actually be involved in the shared decision-making." }\end{array}$ \\
\hline $\begin{array}{l}\text { Patient } \\
\text { autonomy }\end{array}$ & 1 & $\begin{array}{l}\text { "I think the patients should be given a chance to express their opinions independently and that doesn't always } \\
\text { happen." }\end{array}$ \\
\hline
\end{tabular}


other treatment characteristics such as adverse effects, site of treatment and route of treatment were relevant, but not essential for the decision-making process.

A major influencer of treatment choice and subsequent decision is the cost of treatment. Advances in medical sciences such as immunotherapy have brought about this new era of increased response rates and disease survival, while mitigating conventional toxicity associated with chemotherapy. The proportion of patients with myeloma using such novel therapies increased from $8.7 \%$ in 2000 to $61.3 \%$ in $2014 .^{16}$ However, this is not without financial consequences.

In general, healthcare costs have risen faster than the Consumer Price Index, which measures general inflation, for most of the past 40 years ${ }^{17}$ Yet in the case of cancer therapies, the rate of inflation is exceptional, with increase in treatment-related drug costs from an average of 346 USD per patient per month in 2000 to 4179 USD per patient per month in $2014 .{ }^{16}$ For lymphoma, it is estimated that mean monthly healthcare costs amount to 3833 to 5871 USD per patient. ${ }^{18}$ A recent study that followed the trajectory of cancer drug prices after launch found that prices increased by an average of $25 \%$, over a mean follow-up period of 8 years. Even accounting for inflation, the mean cost increase was still $18 \%{ }^{19}$ This trend has also been seen in Australia, where annual expenditure on anticancer drugs has increased by an average of $19 \%$ per annum; the average price paid per prescription, adjusted for inflation, increased by $133 \%$ over 10 years from 2000 to $2012 .^{20}$

For patients and caregivers, however, more directly, this translates into financial toxicity, or increased out-of-pocket payments and associated financial distress. Multiple studies have shown that increased financial toxicity is associated with delayed treatment initiation, ${ }^{21}$ non-compliance to treatment, ${ }^{22}$ lower health-related quality-of-life, ${ }^{23}$ increased risk of depression, ${ }^{24}$ and may even contribute to patients forgoing or delaying medical care after the induction phase of treatment has ended. ${ }^{25}$ Patients who are younger at diagnosis are also significantly more likely to encounter cancerrelated financial problems. ${ }^{25}$ Severe financial difficulties may even be a risk factor for mortality in cancer patients. ${ }^{26}$

This is an issue that needs to be tackled head-on in the initial consults, so that patients, caregivers and physicians are cognizant of the problems and can make informed choices about their preferred treatment options. A recent systematic review suggested that while $60 \%$ of patients had a positive attitude towards cost communication, only
$27 \%$ actually had such a communication with their physician. Assessment of patient satisfaction rating revealed that $80 \%$ of patients had no negative feelings about cost discussions. ${ }^{27}$ In addition, a survey of 300 patients found that cost discussions help to reduce treatment expenses in $57 \%$ of patients. ${ }^{28}$ Satisfaction with financial counselling has also been associated with a reduction in the financial impact of cancer, especially when completed before the start of treatment. ${ }^{29}$

The other interesting finding from our study was that although patients, caregivers and physicians may attribute differing weights to the various treatment characteristics, this was not always communicated effectively between parties. Indeed, even robust tools such as the American Society of Clinical Oncology Value Framework, which accounts for efficacy, toxicity and cost, fail to include consideration of patient preferences. ${ }^{30}$

Shared decision-making has been shown to improve patient satisfaction, ${ }^{31,32}$ treatment adherence, ${ }^{33}$ self-rated health, ${ }^{34}$ confidence in the decision, ${ }^{35}$ patient trust in physicians $^{36}$ and healthcare costs. ${ }^{37}$ In the United States, the Lewin Group has estimated that implementing shared decision-making for just 11 procedures could result in more than US $\$ 9$ billion in savings over 10 years. ${ }^{38}$ Unfortunately, the process is inconsistently realised. A study of 1057 physician-patient encounters encompassing 3552 clinical decisions found that less than $10 \%$ of decisions met criteria for informed decision-making. ${ }^{39}$

Our study adds to the limited but growing literature on the prevalence of shared decision-making across different cultural contexts, demonstrating that a lack of shared decisionmaking persists, even in a setting with Asian cultural norms that purportedly emphasize collective experience and family involvement. ${ }^{40}$ Although patients, caregivers and physicians had different preferences for various treatment characteristics, in practice, these were not always communicated effectively between parties, even within family dyads. Our findings reinforce the notion that culture-based assumptions about decision-making should be avoided, and point to the need for more research in this area.

A possible way to address this may be through the use of decision aids. Decision aids have been proven to improve value-congruent choices. The most recent Cochrane review of the matter was published in 2017 and included 105 studies of 31,043 patients. ${ }^{41}$ Decision aids increased participants' knowledge, risk perception and congruency between individual values and care choices. Decisional conflict, indecision and the proportion of patients who were passive in the 
decision-making process were lower in patients exposed to decision aids, with a positive effect on patient-physician communication. With respect to resource utilisation, the use of decision aids prolonged consultations by a median of only 2.6 mins; healthcare costs were lower in groups using decision aids. ${ }^{41}$

\section{Limitations}

As this was an interview-based study, all responses from participants are subject to recall bias. We tried to address and limit this by also interviewing patients at the time of diagnosis so that their thought processes and feelings were not influenced by time and changing perceptions. However, we also felt that, since myeloma and lymphoma are becoming chronic, relapsing-remitting conditions, that patient and caregiver opinions may change with treatment exposure. Hence, we considered it vital to recruit and interview patients and caregivers across the treatment spectrum, to obtain the breadth of views necessary for such a study.

\section{Conclusion}

The "default" preferred option for most patients is likely to be the treatment deemed most efficacious. However, patients and their caregivers have different concerns, and even when their priorities are relatively aligned (e.g. in the matter of cost) communications may not be open, which can lead to decisions that are potentially sub-optimal. Physicians are generally aware of this, but are presently limited in their ability to manage such conflicts of interest within families, even when their priorities are aligned with those of patients. Acknowledging and managing these differences is paramount because they may affect patient outcomes in the short term, as well as their more general well-being in the long term.

\section{Acknowledgments}

This study was supported by the NCIS-CHSPR Health Services Research Grant and the National Medical Research Council Health Services Research New Investigator Grant. The authors would like to thank Gayatri Kembhavi, Francisco Cervero Liceras, Daniel Junrong Lin, Joel Jun Kai Koh, Violet Lai, Priscella Chia and Fang Fang Song for their help in recruiting participants, organising and coding interviews.

\section{Disclosure}

The authors report no conflicts of interest in this work.

\section{References}

1. Lee HP. Cancer Incidence and Mortality 2003-2012 and Selected Trends 1973-2012 in Singapore. 8 ed. National Registry of Disease Office, Singapore; 2016.

2. Rosenberg PS, Barker KA, Anderson WF. Future distribution of multiple myeloma in the United States by sex, age, and race/ethnicity. Blood. 2015;125:410-412. doi:10.1182/blood-2014-10-609461

3. Tan D, Horning SJ, Hoppe RT, et al. Improvements in observed and relative survival in follicular grade 1-2 lymphoma during 4 decades: the Stanford University experience. Blood. 2013;122:981-987. doi:10.1182/blood-2013-03-491514

4. Moreau P. How I treat myeloma with new agents. Blood. 2017;130:1507-1513. doi:10.1182/blood-2017-05-743203

5. Casulo C, Friedberg JW. Chemotherapy free treatment of indolent lymphoma. Hematol Oncol. 2017;35(Suppl 1):20-24. doi:10.1002/ hon. 2395

6. Piechotta V, Jakob T, Langer P, et al. Multiple drug combinations of bortezomib, lenalidomide, and thalidomide for first-line treatment in adults with transplant-ineligible multiple myeloma: a network meta-analysis. Cochrane Database Syst Rev. 2019;2019. doi:10.1002/ 14651858.CD013487

7. Bonello F, Mina R, Boccadoro M, Gay F. Therapeutic monoclonal antibodies and antibody products: current practices and development in multiple myeloma. Cancers. 2019;12. doi:10.3390/cancers 12010015

8. Apostolidis J, Mokhtar N, Al Omari R, Darweesh M, Al Hashmi H. Follicular lymphoma: update on management and emerging therapies at the dawn of the new decade. Hematol Oncol. Epub 2019 Dec 31.

9. Sindel A, Al-Juhaishi T, Yazbeck V. Marginal zone lymphoma: state-ofthe-art treatment. Curr Treat Options Oncol. 2019;20:90. doi:10.1007/ s11864-019-0687-5

10. Rollig C, Knop S, Bornhauser M. Multiple myeloma. Lancet. 2015;385:2197-2208. doi:10.1016/S0140-6736(14)60493-1

11. Harrison N, Hewitt H, Pandya P, Reisel D. How Montgomery is reconfiguring consent in the UK. Lancet. 2018;392:102-104. doi:10.1016/S0140-6736(18)31124-3

12. Saunders B, Sim J, Kingstone T, et al. Saturation in qualitative research: exploring its conceptualization and operationalization. Qual Quant. 2017;52:1893-1907.

13. Crowe M, Inder M, Porter R. Conducting qualitative research in mental health: thematic and content analyses. Aust $N Z J$ Psychiatry. 2015;49:616-623. doi:10.1177/0004867415582053

14. Vaismoradi M, Turunen H, Bondas T. Content analysis and thematic analysis: implications for conducting a qualitative descriptive study. Nurs Health Sci. 2013;15:398-405. doi:10.1111/ nhs.2013.15.issue-3

15. Tong A, Sainsbury P, Craig J. Consolidated criteria for reporting qualitative research (COREQ): a 32-item checklist for interviews and focus groups. Int $J$ Qual Health Care. 2007;19:349-357. doi:10.1093/intqhe/mzm042

16. Fonseca R, Abouzaid S, Bonafede $M$, et al. Trends in overall survival and costs of multiple myeloma, 2000-2014. Leukemia. 2017;31:1915-1921. doi:10.1038/leu.2016.380

17. Ubel PA, Abernethy AP, Zafar SY. Full disclosure - out-of-pocket costs as side effects. $N$ Engl J Med. 2013;369:1484-1486. doi:10.1056/NEJMp1306826

18. Kutikova L, Bowman L, Chang S, Long SR, Arning M, Crown WH. Medical costs associated with non-Hodgkin's lymphoma in the United States during the first two years of treatment. Leuk Lymphoma. 2006;47:1535-1544. doi:10.1080/10428190600573325

19. Gordon N, Stemmer SM, Greenberg D, Goldstein DA. Trajectories of injectable cancer drug costs after launch in the United States. J Clin Oncol. 2017;36:319-325.

20. Karikios DJ, Schofield D, Salkeld G, Mann KP, Trotman J, Stockler MR. Rising cost of anticancer drugs in Australia. Intern Med J. 2014;44:458-463. doi:10.1111/imj.12399 
21. Winn AN, Keating NL, Dusetzina SB. Factors associated with tyrosine kinase inhibitor initiation and adherence among medicare beneficiaries with chronic myeloid leukemia. $J$ Clin Oncol. 2016;34:4323-4328. doi:10.1200/JCO.2016.67.4184

22. Dusetzina SB, Winn AN, Abel GA, Huskamp HA, Keating NL. Cost sharing and adherence to tyrosine kinase inhibitors for patients with chronic myeloid leukemia. J Clin Oncol. 2014;32:306-311. doi:10.1200/JCO.2013.52.9123

23. Fenn KM, Evans SB, McCorkle R, et al. Impact of financial burden of cancer on survivors' quality of life. $J$ Oncol Pract. 2014;10:332-338. doi:10.1200/JOP.2013.001322

24. Kale HP, Carroll NV. Self-reported financial burden of cancer care and its effect on physical and mental health-related quality of life among US cancer survivors. Cancer. 2016;122:283-289. doi:10.1002/cncr.29808

25. Kent EE, Forsythe LP, Yabroff KR, et al. Are survivors who report cancer-related financial problems more likely to forgo or delay medical care? Cancer. 2013;119:3710-3717. doi:10.1002/cncr.28262

26. Ramsey SD, Bansal A, Fedorenko CR, et al. Financial insolvency as a risk factor for early mortality among patients with cancer. $J$ Clin Oncol. 2016;34:980-986. doi:10.1200/JCO.2015.64.6620

27. Shih YT, Chien CR. A review of cost communication in oncology: patient attitude, provider acceptance, and outcome assessment. Cancer. 2017;123:928-939. doi:10.1002/cncr.30423

28. Zafar SY, Chino F, Ubel PA, et al. The utility of cost discussions between patients with cancer and oncologists. Am J Manag Care. 2015;21:607-615.

29. Buzaglo JS, Miller MF, Karten C, et al. Cancer patient experience with financial counseling among participants of an online registry. $\mathrm{J}$ Clin Oncol. 2016;34:e18265-e. doi:10.1200/JCO.2016.34.15_suppl.e18 265

30. Schnipper LE, Davidson NE, Wollins DS, et al. Updating the American society of clinical oncology value framework: revisions and reflections in response to comments received. J Clin Oncol. 2016;34:2925-2934. doi:10.1200/JCO.2016.68.2518

31. Gattellari M, Butow PN, Tattersall MH. Sharing decisions in cancer care. Soc Sci Med. 2001;52:1865-1878. doi:10.1016/S0277-9536(00) 00303-8
32. Swanson KA, Bastani R, Rubenstein LV, Meredith LS, Ford DE. Effect of mental health care and shared decision making on patient satisfaction in a community sample of patients with depression. Med Care Res Rev. 2007;64:416-430. doi:10.1177/1077558707299479

33. Chambers CV, Markson L, Diamond JJ, Lasch L, Berger M. Health beliefs and compliance with inhaled corticosteroids by asthmatic patients in primary care practices. Respir Med. 1999;93:88-94. doi:10.1016/S0954-6111(99)90296-2

34. Janssen C, Ommen O, Pfaff H, Lefering R, Neugebauer E. Pre-traumatic, trauma- and treatment-related determinants of self-rated health after a severe trauma. Langenbeck's archiv surg. 2009;394:539-546. doi:10.1007/s00423-008-0458-4

35. Burton D, Blundell N, Jones M, Fraser A, Elwyn G. Shared decision-making in cardiology: do patients want it and do doctors provide it? Patient Educ Couns. 2010;80:173-179. doi:10.1016/j. pec.2009.10.013

36. Ommen O, Thuem S, Pfaff H, Janssen C. The relationship between social support, shared decision-making and patient's trust in doctors: a cross-sectional survey of 2197 inpatients using the Cologne Patient Questionnaire. Int J Public Health. 2011;56:319-327. doi:10.1007/ s00038-010-0212-x

37. Arterburn D, Wellman R, Westbrook E, et al. Introducing decision aids at Group Health was linked to sharply lower hip and knee surgery rates and costs. Health Aff (Millwood). 2012;31:2094-2104. doi:10.1377/hlthaff.2011.0686

38. Oshima Lee E, Emanuel EJ. Shared decision making to improve care and reduce costs. $N$ Engl $J$ Med. 2013;368:6-8. doi:10.1056/ NEJMp1209500

39. Braddock $\mathrm{CH}$ 3rd, Edwards KA, Hasenberg NM, Laidley TL, Levinson W. Informed decision making in outpatient practice: time to get back to basics. JAMA. 1999;282:2313-2320. doi:10.1001/jama.282. 24.2313

40. Alden DL, Friend J, Lee PY, et al. Who decides: me or we? Family involvement in medical decision making in eastern and Western countries. Med Decis Making. 2018;38:14-25. doi:10.1177/0272989X17715628

41. Stacey D, Legare F, Lewis K, et al. Decision aids for people facing health treatment or screening decisions. Cochrane Database Syst Rev. 2017;4:Cd001431.
Patient Preference and Adherence

\section{Publish your work in this journal}

Patient Preference and Adherence is an international, peer-reviewed, open access journal that focusing on the growing importance of patient preference and adherence throughout the therapeutic continuum. Patient satisfaction, acceptability, quality of life, compliance, persistence and their role in developing new therapeutic modalities and compounds to optimize clinical outcomes for existing disease states are major areas of interest for the journal. This journal has been accepted for indexing on PubMed Central. The manuscript management system is completely online and includes a very quick and fair peer-review system, which is all easy to use. Visit http:// www.dovepress.com/testimonials.php to read real quotes from published authors. 